\title{
Bio-geoindicadores aplicados ao ecoturismo em Unidades de Conservação localizadas em espaços urbanos
}

\section{Bio-geoindicators applied to the ecotourism in conservation units located in urban spaces}

\author{
Joyce Ferreira Macedo de Andrade Fidélis, Sérgio Queirós Lima, \\ Aline Maria Meiguins de Lima, Márcia Nágem Krag, \\ Quêzia Leandro de Moura Guerreiro
}

\begin{abstract}
RESUMO
As Unidades de Conservação são áreas que visam à proteção da biodiversidade e dos recursos naturais, sua ligação com as práticas de ecoturismo dão suporte ao manejo dessas áreas, uma vez que esta é uma atividade que visa à aproximação dos visitantes e da população do entorno. O presente trabalho teve como objetivo identificar os bio-geoindicadores aplicados ao planejamento de ecoturismo em unidades de conservação localizadas na Região Metropolitana de Belém - Pará (RMB). O método adotado foi de levantamento das práticas do ecoturismo in loco, pesquisa de dados secundários e emprego do modelo "Vulnerabilidade-Pressão-EstadoImpacto-Risco-Resposta", que possibilita identificar os principais elementos de atuação no processo. Os resultados indicaram que as unidades de conservação do Parque Ambiental do Utinga (localizado na Área de Proteção Ambiental de Belém) e do Parque Antônio Danúbio (no município de Ananindeua) são favoráveis ao ecoturismo e a execução continuada de ações de educação ambiental envolvendo as pessoas residentes nas áreas de influência direta destas unidades. Com relação a unidade de conservação do Combu, os bares e restaurantes existentes atuam como atrativos, sendo estratégicos para o turismo local. A análise de "Vulnerabilidade-PressãoEstado-Impacto-Risco-Resposta" demonstrou que as pressões mais intensas são associadas ao crescimento desordenado da RMB, que traz consigo a produção de resíduos, a falta de saneamento, a poluição hídrica e a construção irregular de unidades prediais. As respostas admitidas para a situação de risco instalada indicam que que deve haver uma maior fiscalização dentro dos Parques; e que os projetos que envolvam o turismo sejam mais explorados, com uma maior regularidade e duração.
\end{abstract}

PALAVRAS-CHAVE: Região Metropolitana de Belém; Ecoturismo; Proteção Ambiental. 


\section{ABSTRACT}

The Conservation Units are areas that aimed the protection of biodiversity and the natural resources. Their link with the practices of ecotourism support the management of these areas once this activity aimed the visitor and community approximation. The present project aims to identify the biogeoindicators applied to the planning of ecotourism located in the Metropolitan Region of Belém - Pará (RMB). The survey was conducted based on ecotourism practices on the unit conservations of this study and research of secondary data and documentary. The analysis process employs the model of "Vulnerability-Pressure-State-Impact-Response-Risk", which allows identifying the variables of intervention in each unit. The results specify the practices of ecotourism in the Conservation Units of Utinga Environmental Park (located in Environmental Protection Area of Belém) and Antônio Danúbio Park (in Ananindeua city), proved favorable to ecotourism, through activities on ecological trails and environmental education involving people who live in the areas of direct influence of these units. In the Conservation Units of Combu, bars and restaurants has become only attractive strategy for local tourism. The "Vulnerability-Pressure-State-ImpactResponse-Risk" showed that the most intense pressures are associated with disordered growth of the Metropolitan Region of Belém, which brings with it the production of waste, lack of sanitation, water pollution and the construction of irregular unit buildings. The answers admitted to the risk identified indicate that there should be greater oversight inside the Parks; and the tourism projects must be more explored, with regularity and duration.

KEYWORDS: Metropolitan Region of Belém; Ecotourism; Protection Areas.

\section{Introdução}

Representando umas das melhores estratégias de proteção de patrimônio natural, as áreas protegidas promovem a manutenção de processos ecológicos e a sustentação da biodiversidade local. O Sistema Nacional de Unidade de Conservação (SNUC - Lei n. 9.985/2000) apresenta uma visão estratégica, possibilitando que as Unidades de Conservação (UCs) gerem renda, emprego e desenvolvimento, além da conservação dos ecossistemas, com o intuito de proporcionar uma melhor qualidade de vida às populações locais e aos visitantes dessas áreas (BRASIL, 2012).

O SNUC estabelece critérios e normas para a criação, implantação e gestão das Unidades de Conservação, além de regulamentar dois grupos que estão sobre o gerenciamento das esferas municipais, estaduais e federal: de Proteção Integral e de Uso Sustentável. Dentre as finalidades que podem ser aplicadas tanto a categoria de uso sustentável quanto a algumas formas de proteção integral (ex. Estação Ecológica) está o ecoturismo como forma de valorizar os atributos naturais e possibilitar 0 manejo da área com vistas a manutenção da população residente no local.

Para Conceição et al. (2010) o ecoturismo é visto por diversos autores como a solução apropriada para o uso dos ambientes naturais visando, ao mesmo tempo, sua conservação. Entretanto, esta prática vem sendo utilizada de forma incorreta e predatória. Nesse contexto, projetos que 
facilitam o contato da comunidade local com as unidades de conservação, como, por exemplo, a criação de trilhas ecológicas, criação de ambientes paisagísticos em torno dos mananciais e de educação ambiental, são estratégias que utilizam os recursos naturais para fins turísticos. Esses projetos podem desenvolver a sensibilização da população do entorno, resgatando a conscientização sobre a importância da conservação.

Porém, para que haja a implementação de projetos com essas características é necessário haver um planejamento ambiental, pois se realizados de maneira inadequada pode causar danos as unidades de conservação. Esse planejamento é baseado em diagnósticos ambientais utilizando indicadores variados para avaliar as condições do ambiente, resultando na concepção de um plano de manejo.

Dentre os elementos necessários a concepção de um bom plano de manejo está a definição dos principais critérios definidores dos potenciais e limitantes de cada UC; para tanto podem ser empregados biogeoindicadores que segundo Goulart e Callisto (2003) focalizam as mudanças naturais e também as introduzidas pelo homem no ambiente.

O termo bioindicador deriva do uso específico de indicadores bióticos (fauna e flora) para determinada finalidade (FREITAS; SIQUEIRA-SOUZA, 2009). Como exemplo, cita-se o controle da qualidade da água. Dentre os bioindicadores aquáticos destacam-se os peixes (como bioacumuladores de metais) e a ocorrência de macrófitas, cuja associação com a poluição gerada pelo acúmulo de matéria orgânica (resíduos) pode ser um indicador de alteração da qualidade (SILVA et al., 2012). A possibilidade de realizar um diagnóstico rápido caracterizando tal aspecto é importante, principalmente quando se trata de mananciais voltados ao abastecimento público (VASCONCELOS et al., 2011).

Os geoindicadores foram introduzidos a partir de 1994 através da Comissão de Ciências Geológicas para o Planejamento Ambiental (Cogeoenvironment) e da União Internacional de Ciências Geológicas (IUGS) (TAVARES et al., 2007). Neste contexto, Júnior e Villa (2011) sugerem que os geoindicadores são uma forma de diagnosticar evidencias geológicas, geomorfológicas e os processos que originam mudanças de curto prazo de cem anos ou menos. Conceição et al. (2010) os conceitua como ferramentas normativas que devem contribuir na resposta para as quatro questões básicas: $O$ que está acontecendo? (condições e tendências); Por que está acontecendo? (causas, humanas e/ou naturais); Por que é importante? (efeitos ecológicos, econômicos e na saúde); o que se pode fazer acerca disso? (implicações no planejamento e nas políticas).

Logo, o termo bio-geoindicador é usado para classificar grupos bióticos, abióticos, humanos e sociais que possuem alguma sensibilidade para certos fatores que ocorrem no ambiente ou geralmente indicam perturbações de ações antropogênicas (GOULART; CALLISTO, 2003; MESTRE; GASNIER, 2008). Estes mostram as áreas em processo de degradação com aberturas de clareiras (naturais ou antrópicas), poluição de rios por meio da eutrofização e o manejo inadequado do solo. Tais atividades precisam ser controladas para que as consequências não cheguem à perda da biodiversidade e/ou afetem o ser humano (BAHIA et al., 2010). 
As atividades turísticas trouxeram benefícios para inúmeros setores da economia, mas também provocaram diversos impactos negativos, no aspecto natural e cultural. O termo ecoturismo é traduzido como uma solução para o uso adequado de ambientes naturais, visando sua conservação. Sua prática está diretamente ligada com o deslocamento de pessoas para espaços que são delimitados e protegidos oficialmente pelo Estado (CONCEIÇÃO et al., 2010).

Em 1994, o Ministério do Meio Ambiente (MMA), em parceria com o Instituto Brasileiro de Turismo (EMBRATUR), o Instituto Brasileiro do Meio Ambiente e Recursos Naturais Renováveis (IBAMA), e diversos profissionais, lançaram as "Diretrizes para Elaboração de uma Política Nacional do Ecoturismo" que conceitua o ecoturismo como um segmento de atividades turísticas, utilizando de forma sustentável, o patrimônio natural e cultural, além do incentivo a conservação e a busca do desenvolvimento de uma consciência ambientalista através da interpretação do ambiente, gerando o bem-estar das populações relacionadas (SILVA et al., 2008).

A relação entre o turismo e o meio ambiente é muito intrínseca, especialmente quando se trata de unidades de conservação. As atividades turísticas se baseiam na relação sustentável com a natureza, além das comunidades receptoras que estão comprometidas com a conservação, educação ambiental e o desenvolvimento socioeconômico (BRASIL, 2010).

Visto a importância do uso dos bio-geoindicadores para 0 planejamento do ecoturismo, foi realizado um diagnóstico empregando a técnica VPSIR (Vulnerability - Vulnerabilidade; Pressures - Pressão; States Estado; Impacts - Impacto e Responses - Resposta), visando à proposição de medidas de manejo aplicadas ao ecoturismo para três unidades de conservação localizadas na Região Metropolitana de Belém (RMB).

O modelo VPSIR como sistema de suporte à decisão, representa uma forma de análise que visa fornecer subsídios a gestão territorial; deriva do modelo PER (Pressures - State - Responses) adaptado pela OCDE (Organização Europeia de Cooperação Econômica) com o objetivo de perceber as ligações existentes entre o ambiente através dos indicadores ambientais e da sociedade através do desempenho ambiental (OECD, 2011; SONG; FROSTELL, 2012). Sua aplicação possibilita avaliar a dinâmica das atividades econômicas e do comportamento humano sobre a qualidade ambiental, reforçando a interação entre as causas dos problemas ambientais, os impactos e as respostas da sociedade, de uma forma integrada.

Segundo Borja et al. (2006), fornece um mecanismo global para análise de problemas ambientais. Deste modo, as Vulnerabilidades são referentes as características do meio de análise; e consideradas como sendo políticas econômicas e sociais dos governos. As Pressões são os caminhos que estes elementos condutores são expressos e o modo como os ecossistemas e seus componentes são perturbados. Essas pressões afetam o Estado do ambiente, que consequentemente geram Impactos na saúde humana e nos ecossistemas, obrigando a formulação de respostas. Estas últimas dar-se-ão por meio de várias medidas de política, tais como regulamentos, informações, impostos e planos diretores municipais. 


\section{Material e método}

No presente estudo foram consideradas três UCs: Parque Estadual do Utinga na Área de Proteção Ambiental (APA) de Belém; Área de Proteção Ambiental Ilha do Combu; e o Parque Ambiental de Ananindeua "Antônio Danúbio" (Figura 1).
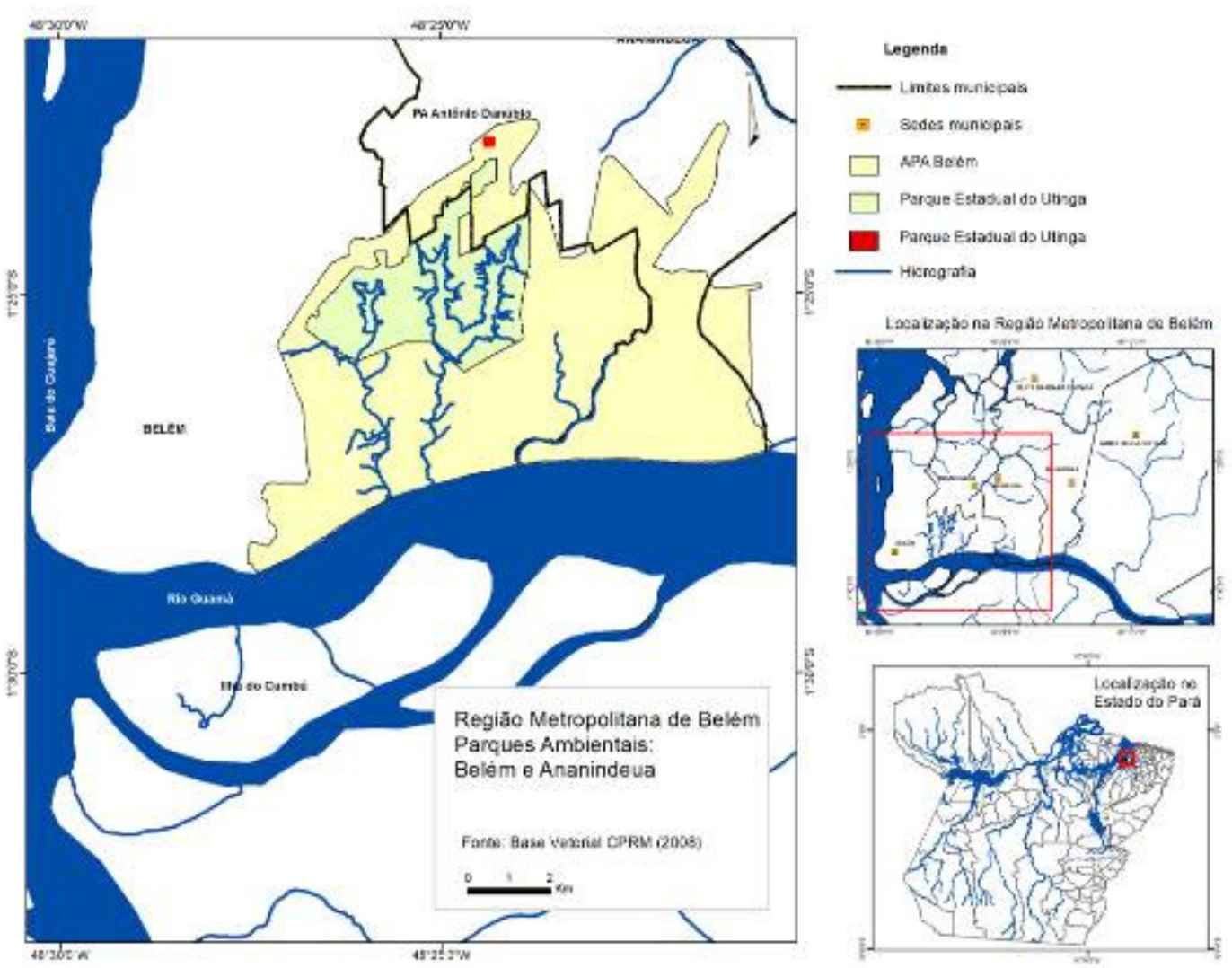

Figura 1: Localização geral das áreas de estudo.

Figure 1: Location of study areas.

O Parque Estadual do Utinga na APA Belém, localizado na Avenida João Paulo II, região Metropolitana de Belém, foi criado a partir do Decreto $\mathrm{n}^{\circ} 1.552$, de 03 de maio de 1993, sendo uma UC de Proteção Integral com 1.393 hectares. A Área de Proteção Ambiental (APA), denominada llha do Combu, que se insere ao grupo de uso sustentável no SNUC, foi criada pela Lei n 6.083 de 13/11/1997, localiza-se na margem esquerda do Rio Guamá, inserida a nordeste do município de Belém, PA. E a UC Parque Ambiental de Ananindeua "Antônio Danúbio", foi criada em 01 de outubro de 2012, situase na Rodovia BR 316, Km 05, Região Metropolitana de Belém.

A pesquisa realizada apresentou um perfil exploratório de acordo com Varela e Carvalho (2009); e os procedimentos adotados constaram (Figura 2): da investigação documental direta procurando informações sobre as UCs em estudo em seus órgãos de gerenciamento; do levantamento por meio de entrevistas, junto aos gestores estaduais e municipais das UCs, para apoiar a interpretação dos documentos consultados, junto aos órgãos gestores do estado e municipais; da análise cartográfica da área de entorno das UCs; da identificação dos possíveis bio-geoindicadores que podem ser aplicados as 
UCs; da análise destes fatores empregando o modelo VPSIR (Vulnerability Vulnerabilidade; Pressures - Pressão; States - Estado; Impacts - Impacto e Responses - Resposta) a partir das observações de campo; ao final, os dados identificados foram simulados para avaliar a sustentabilidade as práticas de ecoturismo empregadas nas UCs estudadas, aplicando uma adaptação do modelo proposto por Rissik et al. (2005).

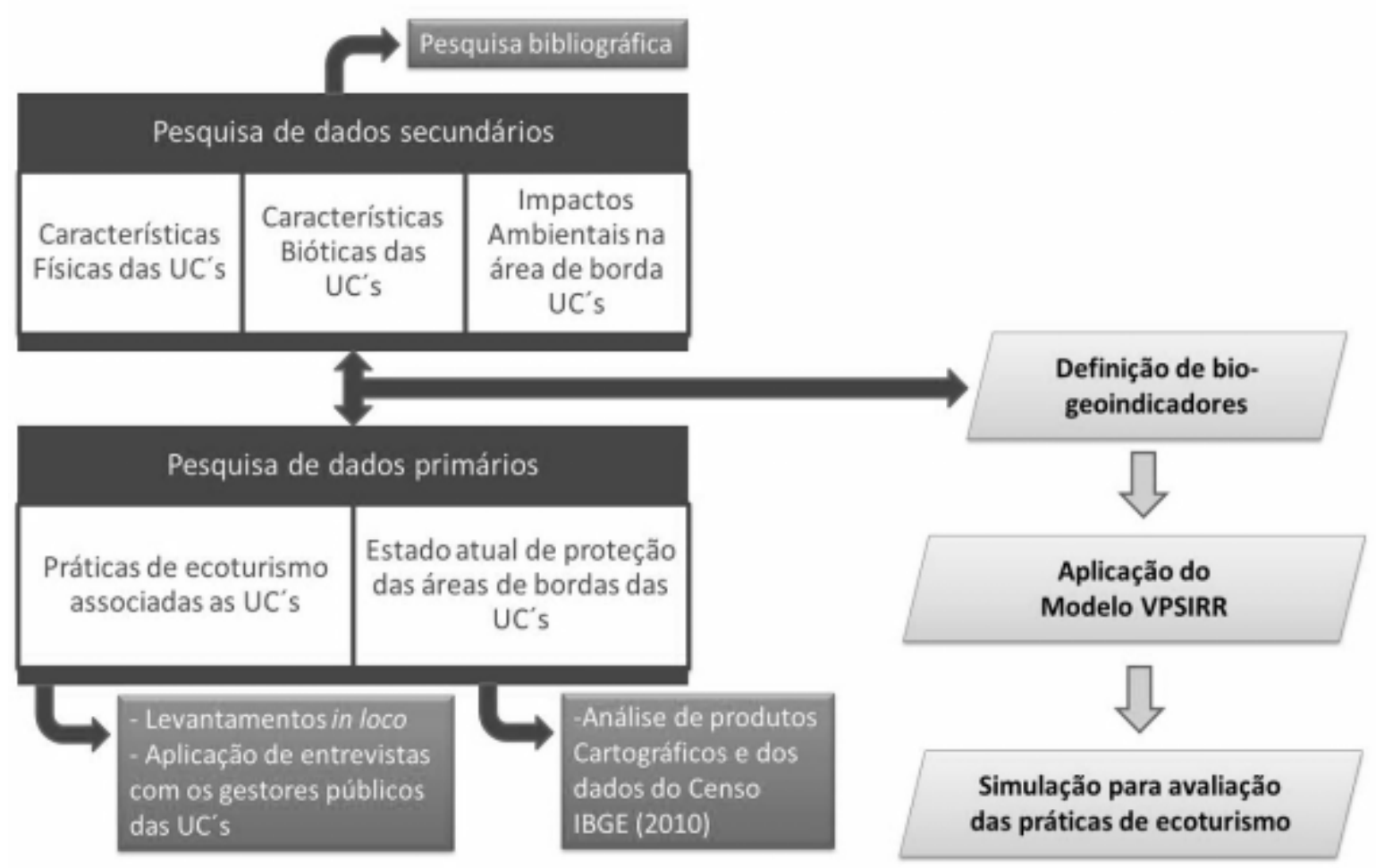

Figura 2: Fluxograma da metodologia adotada.

Figure 2: Flowchart of the methodology adopted.

As entrevistas efetuadas junto aos gestores administrativos (do estado e municipais) das UC's pesquisadas buscaram investigar: os atuais e futuros projetos desenvolvidos em cada unidade; as condições de implementação de práticas de ecoturismo existentes e previstas; os principais recursos que podem ser explorados; as pressões antrópicas existentes; e as iniciativas para amenizar o impacto ambiental existente.

As informações coletadas nas etapas de levantamento secundário (bibliográfico e documental) e de campo foram analisados empregando duas formulações. A primeira objetiva estabelecendo as relações entre as variáveis existentes por meio do modelo VPSIR visando estabelecer as relações existentes entre as variáveis (Figura 3, Tabela 1); no sentido de entender como os elementos de ocupação do entorno das UCs pesquisadas interagem entre si e podem afetar as mesmas:

- Vulnerabilidade: os Parques apresentam vulnerabilidades que facilitam a ação dos elementos de pressão.

- Pressão: são fatores que agem diretamente sobre os Parques, em função das forças externas que atuam. 
- Estado: implica em como os Parques se encontram atualmente em função da ação das pressões existentes.

- Impacto: significa as consequências resultantes da interação entre pressão e estado.

- Risco: é decorrente da vulnerabilidade, considerando a permanência dos fatores de pressão.

- Resposta: implica nas ações que o poder público exerce para minimizar os problemas existentes e favorecer a preservação destas áreas.

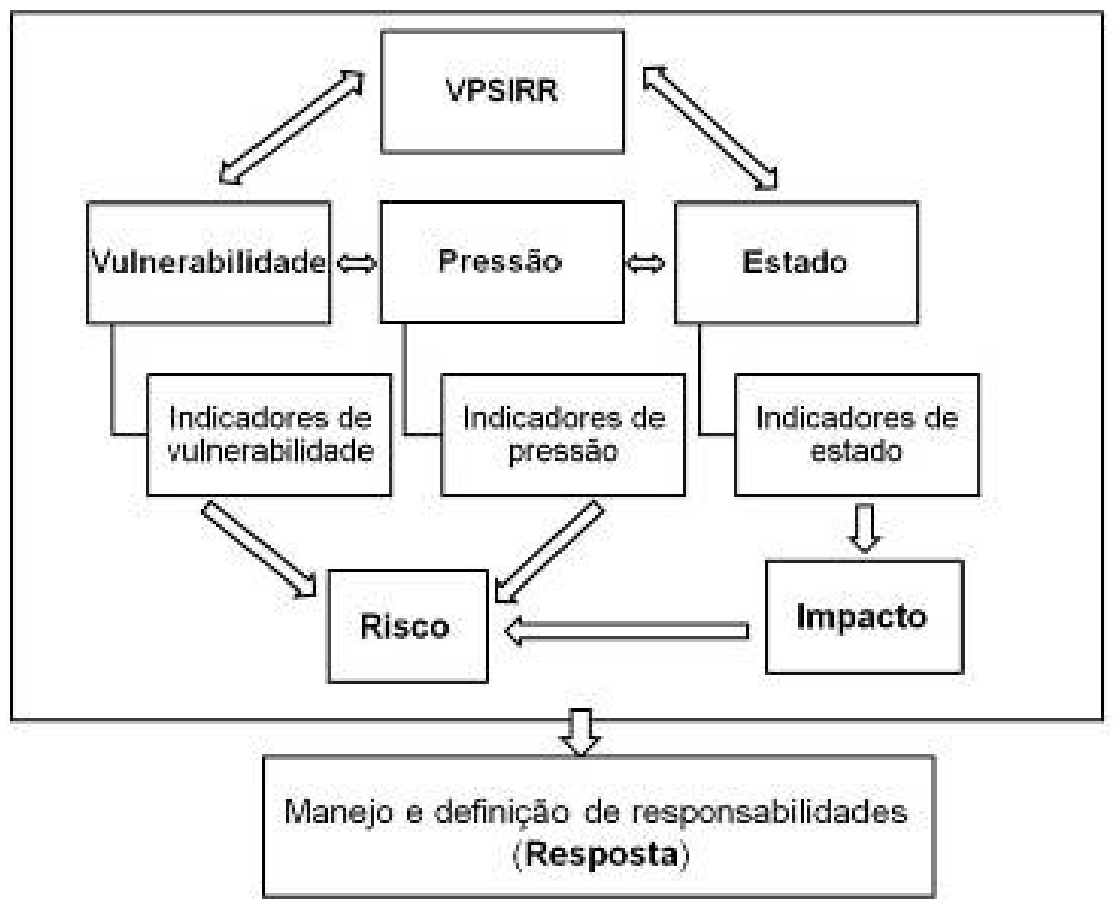

Figura 3: Estrutura do modelo VPSIRR. Fonte: Adaptado de Rissik et al. (2005).

Figure 3: Structure of VPSIRR model. Source: Adapted from Rissik et al. (2005).

Tabela 1 - Parâmetros avaliados na caracterização das áreas.

Table 1 - Parameters evaluated in the areas characterization.

\begin{tabular}{|l|l|l|l|l|l|}
\hline \multicolumn{1}{|c|}{ Força Motriz } & \multicolumn{1}{|c|}{ V } & \multicolumn{1}{c|}{ P } & \multicolumn{1}{c|}{ E } & \multicolumn{1}{c|}{ I } & \multicolumn{1}{c|}{ R } \\
\cline { 2 - 6 } & Vulnerabilidade & Pressão & \multicolumn{1}{c|}{ Estado } & \multicolumn{1}{c|}{ Impacto } & Resposta \\
\hline Arbanização & $\begin{array}{l}\text { Áreas verdes ou } \\
\text { presença de } \\
\text { ambientes } \\
\text { sensíveis }\end{array}$ & $\begin{array}{l}\text { Número de } \\
\text { residéncias } \\
\text { residenciais } \\
\text { próximas a } \\
\text { áreas verdes } \\
\text { ou ambientes } \\
\text { sensíveis }\end{array}$ & $\begin{array}{l}\text { Fragmentação } \\
\text { de ambientas } \\
\text { florestais }\end{array}$ & $\begin{array}{l}\text { Políticas } \\
\text { públicas } \\
\text { propostas }\end{array}$ \\
\hline $\begin{array}{l}\text { Saneamento } \\
\text { básico: } \\
\text { abastecimento de } \\
\text { água e lançamento } \\
\text { de esgotos }\end{array}$ & $\begin{array}{l}\text { Grau de } \\
\text { cobertura }\end{array}$ & $\begin{array}{l}\text { Eficiência } \\
\text { precariedad } \\
\text { e) do } \\
\text { atendimento }\end{array}$ & $\begin{array}{l}\text { Nível de } \\
\text { alteração (ou } \\
\text { degradação) } \\
\text { existente }\end{array}$ & $\begin{array}{l}\text { Consequências } \\
\text { sobre a } \\
\text { qualidade } \\
\text { ambiental }\end{array}$ & $\begin{array}{l}\text { Planos e } \\
\text { programas } \\
\text { implantados }\end{array}$ \\
\hline $\begin{array}{l}\text { Desenvolvimento } \\
\text { de práticas } \\
\text { educativas }\end{array}$ & $\begin{array}{l}\text { Integração das } \\
\text { ações com a } \\
\text { comunidade }\end{array}$ & $\begin{array}{l}\text { Frequência } \\
\text { e } \\
\text { continuidade } \\
\text { das ações }\end{array}$ & $\begin{array}{l}\text { Fragilidade (ou } \\
\text { potencial) das } \\
\text { ações } \\
\text { implantadas }\end{array}$ & $\begin{array}{l}\text { Falta de adesão } \\
\text { (ou integração) } \\
\text { da comunidade }\end{array}$ & $\begin{array}{l}\text { Fortalecimento } \\
\text { das ações } \\
\text { educativas } \\
\text { propostas }\end{array}$ \\
\hline
\end{tabular}


A segunda etapa, empregou variáveis apontadas pelo modelo como as que exercem maior pressão e que podem influenciar diretamente as atividades de ecoturismo na área, e as classificaram segundo seu grau de influência (Figura 4):

- Alto: impedem o desenvolvimento da atividade se não forem resolvidos.

- Moderado: não impedem completamente o desenvolvimento da atividade, mas dificultam seu andamento devendo ser gerenciadas.

- Baixo: não impedem o desenvolvimento da atividade, podendo ser gerenciadas.

\section{Etapa 1. Matriz 5x5}

Foram considerados bio-geoindicadores os elementos de vulnerabilidade identificados.

Estes foram relacionados com os elementos de pressão para a avaliação de risco ao desenvolvimento das práticas de ecoturismo quem representa o maior obstáculo, implicará no maior risco:

- Peso 5 e 4 (alto): impedem o desenvolvimento da atividade se não forem resolvidos.

- Peso 3 (Moderado): não impedem completamente o desenvolvimento da atividade, mas dificultam seu andamento devendo ser gerenciadas.

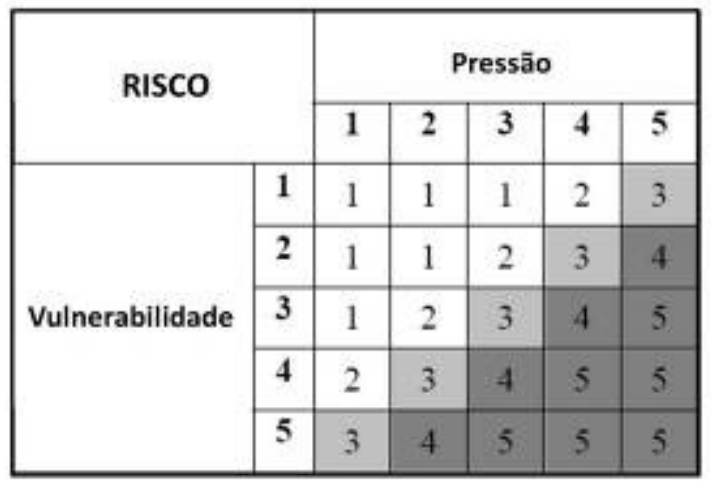

- Peso 1 e 2 (Baixo): não impedem o desenvolvimento da atividade, podendo ser gerenciadas.

\section{Etapa 2. Matriz $5 \times 5$}

Foram avaliadas a relação entre o grau de risco atribuído e o estado atual que se encontra:

- Peso 5 e 4 (alto): a situação de risco está instalada.

- Peso 3 (Moderado): a situação de risco está em processo de instalação.

- Peso 1 e 2 (Baixo): a situação de risco não existe ou é incipiente.

\begin{tabular}{|c|c|c|c|c|c|c|}
\hline \multicolumn{2}{|c|}{} & \multicolumn{5}{|c|}{ Estado } \\
\cline { 2 - 7 } \multicolumn{2}{|c|}{} & $\mathbf{1}$ & $\mathbf{2}$ & $\mathbf{3}$ & $\mathbf{4}$ & $\mathbf{5}$ \\
\hline \multirow{4}{*}{ Risco } & $\mathbf{1}$ & 3 & 3 & 3 & 2 & 1 \\
\cline { 2 - 7 } & $\mathbf{2}$ & 3 & 3 & 2 & 1 & 2 \\
\cline { 2 - 7 } & $\mathbf{3}$ & 3 & 2 & 1 & 2 & 3 \\
\cline { 2 - 7 } & $\mathbf{4}$ & 2 & 1 & 2 & 3 & 3 \\
\cline { 2 - 7 } & $\mathbf{5}$ & 1 & 2 & 3 & 3 & 3 \\
\hline
\end{tabular}

Figura 4: Análise de risco aplicada as práticas de ecoturismo nas UCs de estudo. Figure 4: Risk analysis applied to practices of ecotourism in protected areas of study.

A avaliação do risco foi realizada por meio da relação entre as variáveis de maior "Vulnerabilidade", que representam os bio-geoindicadores e as de "Pressão"; estes elementos foram avaliados e empregados pesos, quanto maior o risco para o desenvolvimento das práticas de ecoturismo, maior era o peso, que variam de um (mais baixo) a cinco (mais alto). Em função do dimensionamento das matrizes os dados foram avaliados empregando o teste Shapiro-Wilk (RAZALI; WAH, 2011) para identificação do comportamento tendencial das variáveis analisadas e a determinação da 
mediana e das faixas percentuais de permanência (quartis) para definição da situação de maior frequência de risco (software Statistics).

\section{Resultados}

\section{Práticas de ecoturismo aplicadas nas unidades de conservação}

No Parque Estadual do Utinga na APA Belém e no Parque Antônio Danúbio existem projetos que envolvem a educação ambiental e trilhas interpretativas, sendo esta última a mais explorada entre as duas UCs. Porém, quando observada a dinâmica das trilhas ecológicas, a do Parque do Utinga apresenta uma maior riqueza de contemplação da natureza, por conta da grande biodiversidade que pode ser vista ao longo do trajeto. Diferente do Parque de Ananindeua, que não possui uma diversidade biológica grande, mas em compensação há o atrativo das trilhas interpretativas que são acompanhadas pela educação ambiental.

A prática da educação ambiental por meio das trilhas ecológicas tem se mostrado como uma boa alternativa para a sensibilização da população que visita os Parques conforme evidenciado por Pedrini (2006), além do atrativo para a contemplação da natureza. Quando estas trilhas são acompanhadas principalmente com interpretações de funcionários que procuram transmitir a educação ambiental, a estratégia fica ainda mais completa.

A visita de escolas em uma UC é de fundamental importância para a difusão do conhecimento sobre a preservação do meio ambiente. A educação ambiental realizada com crianças dentro dos parques ambientais proporciona resultados mais satisfatórios, visto que é mais fácil construir uma sensibilização do que em adultos, conforme constatado por Bezerra e Gonçalves (2007).

A UC da llha do Combu ainda não apresenta projetos que venham a explorar as trilhas ecológicas da llha para a função do turismo, há apenas seis bares e restaurantes. O grande diferencial desta UC para as demais, está na existência de uma forte atividade comercial vinculada a ações de turismo implantadas por iniciativas associadas ao investimento privado local e pelo poder público estadual. Como exemplo, citam-se os passeios de barco promovidos por empresas de turismo nos "furos" (canais de drenagem que cortam a ilha), para a realização da contemplação da natureza dos turistas, é importante frisar que na maioria destes passeios os visitantes não chegam a desembarcar na ilha.

A Illha do Combu não apresenta praias, por ser uma ilha tipicamente fluvial e de ambiente de várzea; como alternativa são implantados bares e restaurantes, que promovem um cardápio com comidas regionais (como o consumo do açaí produzido localmente) e uma programação que valoriza práticas culturais (música e dança) típicas do Pará. Como comparação, no município de Bonito no Mato Grosso do Sul, os bares e restaurantes utilizam da gastronomia local como atração (LAMOSO; LOMBA, 2006). É importante ressaltar que na maioria destes estabelecimentos, a decoração remete a atitudes do povo local, cultura e sociedade.

Todos os elementos que possam contribuir para o ecoturismo local devem estar ligados a indicadores que permitam avaliar a implementação destas práticas. Pois esta análise possibilita prever se o Parque está apto para fomentar os projetos, sem afetar o meio natural e nem como inserir a população do entorno, para que esta última venha a contribuir para a diminuição da pressão e vulnerabilidade nas margens destas unidades (FERREIRA et al., 2005). 


\section{Avaliação das vulnerabilidades}

A Área de Proteção Ambiental de Belém apresenta uma grande faixa impactada (Figura 5) que totalizam $24.28 \mathrm{~km}^{2}$. Deste valor, $12.54 \mathrm{~km}^{2}$ (51.68\%) estão dentro da faixa de até $500 \mathrm{~m}$ e $18.19 \mathrm{~km}^{2}(74.92 \%)$ de até $1 \mathrm{~km}$, em ambos os casos é observado o limite a partir da borda para seu interior (Figura 6).

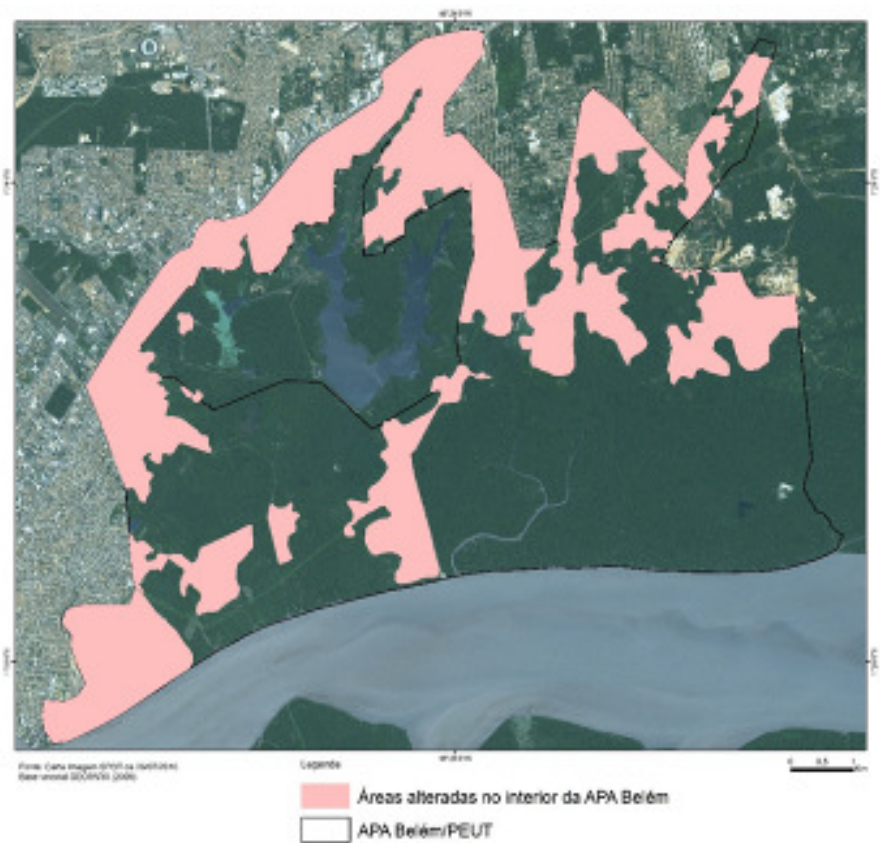

Figura 5: Áreas alteradas no interior da APA Belém.

Figure 5: Areas altered inside the APA Belém.

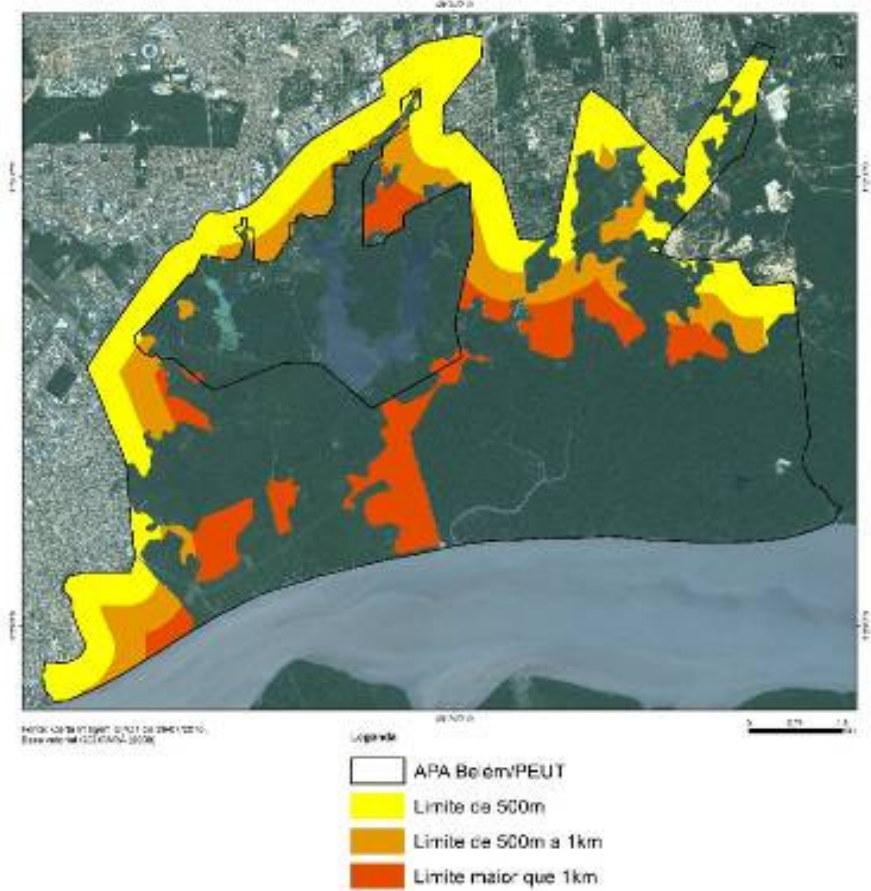

Figura 6: Limite da APA Belém em três níveis de impacto.

Figure 6: Limit of the APA Belém in three levels of impact.

Os dados mostram que já existem consideráveis áreas desmatadas no Parque Estadual do Utinga; mesmo sendo uma UC de proteção integral. Estas são causadas principalmente pelo aumento da Região Metropolitana de Belém (RMB) ao norte, onde a periferia invade a fim de fixar residência; e também pela utilização dos recursos naturais, como a construção de estruturas para a captação do recurso hídrico (BAÍA JÚNIOR; GUIMARÃES, 2004).

As áreas alteradas no interior da APA representam a infra estrutura da Companhia de Saneamento do Estado do Pará (COSANPA) que atua manutenção dos lagos Bolonha e Água Preta, responsáveis pelo abastecimento de água do município de Belém; e produto de sucessivas tentativas de ocupação da área da APA por pessoas que veem neste espaço um ambiente que deve ser destinado a ocupação e não a preservação ou conservação. O poder público estadual e municipal atua na desocupação frequente destas áreas, porém algumas já conseguiram se estabelecer, como é o caso das áreas de periferia já implantadas e consolidadas no seu entorno.

O Parque "Antônio Danúbio" é uma área preservada que se mantém, mesmo com as várias pressões no seu entorno. A APA da llha do Combu, por outro lado, possui a sua área verde quase que totalmente preservada, 
possivelmente isto pode estar relacionado ao seu distanciamento do centro da $\mathrm{RMB}$, ou seja, existe menos pressão sobre ela do que em relação às outras UCs (Figura 7).

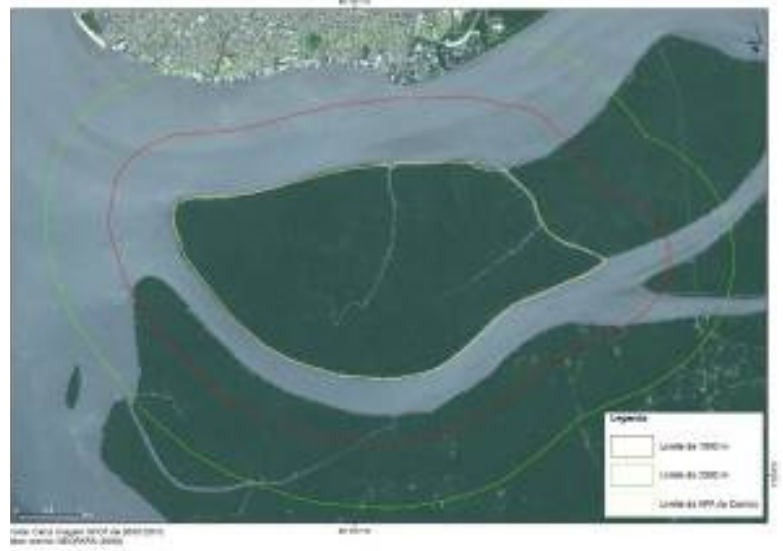

(a)

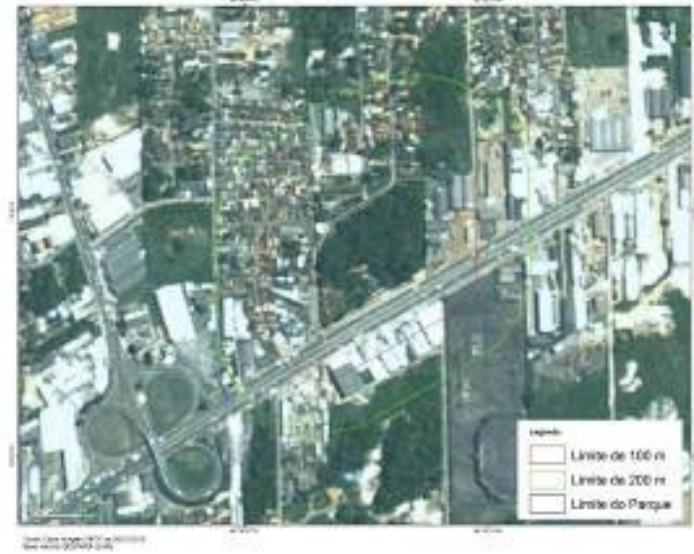

(b)

Figura 7: Limites das linhas equidistantes das bordas (a) da APA Combu; (b) do Parque Ambiental de Ananindeua "Antônio Danúbio".

Figure 7: Limits of the buffer analysis: (a) APA Combu; (b) Environmental Park of Ananindeua "Antônio Danúbio".

A Figura 7a demonstra que a APA Combu, dado seu aspecto insular, tem sua zona de interface com o continente em uma faixa superior a $2 \mathrm{~km}$, enquanto que o Parque "Antônio Danúbio" tem uma ampla urbanização na faixa de $100 \mathrm{~m}$. Este efeito de borda das duas áreas apesar de diferente natureza, representam pressões contínuas, pelo crescimento do espaço urbano e necessidade de ampliação de mercados; que no caso da llha do Combu, dada sua proximidade com Belém, é um espaço visado pelo setor hoteleiro que só investe na área na questão de alimentação (restaurantes); e o entorno do Parque "Antônio Danúbio" atrai o setor imobiliário que enxerga na proximidade de áreas verdes uma forma de valorização de imóveis.

Com a análise quantitativa e qualitativa é possível indicar a pressão que os ambientes estão sofrendo no entorno das UCs estudadas no presente trabalho. Ressalta-se que aplicação de práticas de ecoturismo dentro das UCs se faz necessário principalmente para realização da sensibilização da comunidade focando na preservação destas áreas que possuem algum recurso natural de extrema vulnerabilidade.

\section{Bio-geoindicadores aplicados as práticas de ecoturismo}

As variáveis selecionadas possibilitaram construir o quadro necessário à avaliação do modelo VPSIR (Vulnerability - Vulnerabilidade; Pressures - Pressão; States - Estado; Impacts - Impacto e Responses Resposta) e sua consequente avaliação de risco. Para identificar os fatores condicionantes do processo foi necessário caracterizar as chamadas "Forças Motrizes" que favorecem ou induzem determinado comportamento, empregando informações obtidas por levantamentos de dados secundários e primários de campo. Estas foram: o avanço imobiliário; o abastecimento de água irregular e lançamento de esgoto doméstico no sistema coletor público 
e nas redes de drenagem pluviais; o acúmulo de resíduos sólidos; o desmatamento; o exercício da caça e da pesca; e o desenvolvimento de práticas de educação ambiental.

A Tabela 1 apresenta os dados indicadores das "variáveis de análise", obtidos a partir do cruzamento dos dados de campo (área de influência direta das UCs) com as informações do Censo IBGE (2010). A Tabela 2 representa a análise matricial de "Pressão" x "Vulnerabilidade" obtida para cada unidade (Figura 4 - Etapa 1): Parque Estadual do Utinga na APA Belém $(4 \times 7)$, Área de Proteção Ambiental Ilha do Combu $(4 \times 4)$ e Parque Ambiental de Ananindeua "Antônio Danúbio" (4 x 4).

Tabela 1: Variáveis de análise admitidas.

Table 1: Variables of analysis admitted.

\begin{tabular}{|c|c|c|c|}
\hline \multirow{2}{*}{$\begin{array}{l}\text { Variáveis de } \\
\text { análise }\end{array}$} & \multicolumn{3}{|c|}{ Características } \\
\hline & APA Belém & APA do Combu & $\begin{array}{l}\text { Parque Antônio } \\
\text { Danúbio }\end{array}$ \\
\hline $\begin{array}{l}\text { Número de } \\
\text { domicílios }\end{array}$ & 11608 domicílios & 301 domicílios & 1573 domicílios \\
\hline $\begin{array}{l}\text { Abastecimento } \\
\text { de água }\end{array}$ & $\begin{array}{l}2484 \text { utilizam água de } \\
\text { rede geral, } 389 \text { utilizam } \\
\text { poço ou nascente }\end{array}$ & $\begin{array}{l}259 \text { residências possuem formas } \\
\text { alternativas de obtenção da água: } \\
\text { captação da chuva ou compram } \\
\text { água para o consumo próprio e } \\
\text { usam o rio para os demais usos }\end{array}$ & $\begin{array}{c}1123 \text { utilizam } \\
\text { água de poço ou } \\
\text { nascente }\end{array}$ \\
\hline $\begin{array}{l}\text { Lançamento } \\
\text { de esgoto }\end{array}$ & $\begin{array}{c}2913 \text { residências com } \\
\text { banheiro exclusivo e } 48 \\
\text { não apresentam }\end{array}$ & $\begin{array}{l}251 \text { residências possuem banheiro } \\
\text { de uso exclusivo, e } 9 \text { não possuem }\end{array}$ & $\begin{array}{c}1444 \text { residências } \\
\text { com banheiro } \\
\text { exclusivo }\end{array}$ \\
\hline $\begin{array}{l}\text { Coleta de } \\
\text { resíduos }\end{array}$ & $\begin{array}{l}5786 \text { residências com } \\
\text { lixo coletado e } 62 \text { tem } \\
\text { outro destino, em geral } \\
\text { associado a queima ou o } \\
\text { depósito em locais } \\
\text { escavados no solo }\end{array}$ & $\begin{array}{l}254 \text { residências queimam seu lixo e } \\
4 \text { residências dão outro destino }\end{array}$ & $\begin{array}{c}2898 \text { residências } \\
\text { com lixo } \\
\text { coletado }\end{array}$ \\
\hline
\end{tabular}

Tabela 2: Análise da matriz "Vulnerabilidade" x "Pressão", considerando os pesos: 5 e 4 (alto); 3 (Moderado); e 1 e 2 (Baixo).

Table 2: Analysis of "Vulnerability" $x$ "Pressure" matrix, considering the weights: 5 and 4 (high), 3 (Moderate), 1 and 2 (Low).

\begin{tabular}{|c|c|c|c|c|}
\hline \multirow[b]{2}{*}{ Vulnerabilidades } & \multicolumn{4}{|c|}{ Pressão - Parque Estadual do Utinga na APA Belém } \\
\hline & $\begin{array}{c}\text { N. de } \\
\text { domicílios }\end{array}$ & $\begin{array}{l}\text { Abastecimen- } \\
\text { to de água }\end{array}$ & $\begin{array}{c}\text { Lançamento } \\
\text { de esgoto }\end{array}$ & $\begin{array}{l}\text { Coleta de } \\
\text { resíduos }\end{array}$ \\
\hline Proximidade de áreas verdes & 3 & 1 & 1 & 3 \\
\hline Fluxo de água & 2 & 4 & 3 & 1 \\
\hline Escoamento do esgoto para corpos hídricos & 5 & 4 & 4 & 3 \\
\hline Infiltração no solo de líquido residual & 5 & 4 & 4 & 3 \\
\hline Fauna terrestre de fácil acesso à caça & 5 & 1 & 1 & 1 \\
\hline Pesca pelo acesso ao Parque & 5 & 1 & 1 & 1 \\
\hline \multirow[t]{2}{*}{ Extrativismo vegetal de livre acesso } & 5 & 1 & 1 & 1 \\
\hline & \multicolumn{4}{|c|}{ Pressão - APA do Combu } \\
\hline Proximidade de áreas verdes & 2 & 1 & 2 & 4 \\
\hline Fluxo de água & 2 & 2 & 4 & 2 \\
\hline Escoamento do esgoto para corpos hídricos & 4 & 4 & 4 & 3 \\
\hline \multirow[t]{2}{*}{ Ameaça de focos de incêndio } & 5 & 4 & 5 & 4 \\
\hline & \multicolumn{4}{|c|}{ Pressão - Parque Antônio Danúbio } \\
\hline Proximidade de áreas verdes & 3 & 1 & 1 & 1 \\
\hline $\begin{array}{l}\text { Fluxo de água } \\
\end{array}$ & 1 & 4 & 1 & 1 \\
\hline Escoamento do esgoto para corpos hídricos & 4 & 4 & 4 & 2 \\
\hline Infiltração de líquido residual no solo & 5 & 5 & 3 & 2 \\
\hline
\end{tabular}


O teste Shapiro-Wilk indicou uma distribuição normal para a relação analisada (vulnerabilidade e pressão), a exceção do Parque Estadual do Utinga na APA Belém, que destaca-se pela complexidade de variáveis associadas, resultantes principalmente do intenso antropismo do entorno (Figura 8).

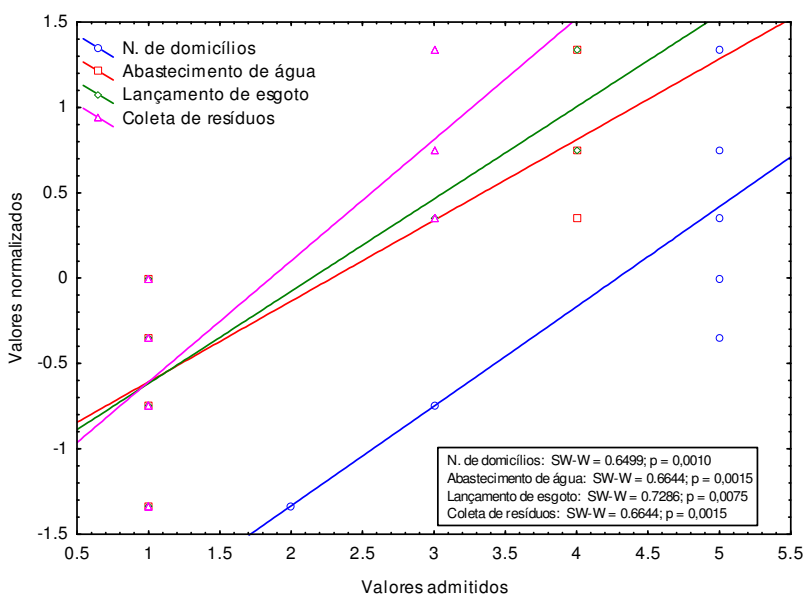

(a)

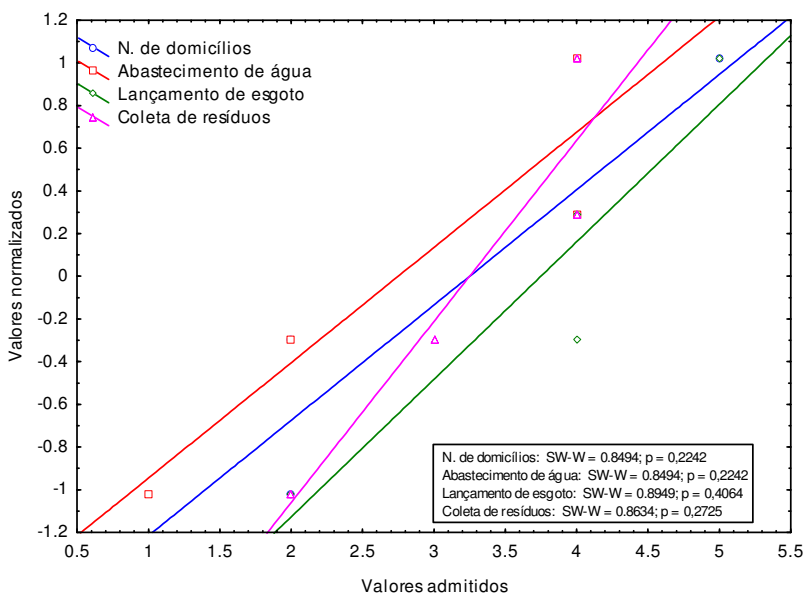

(b)

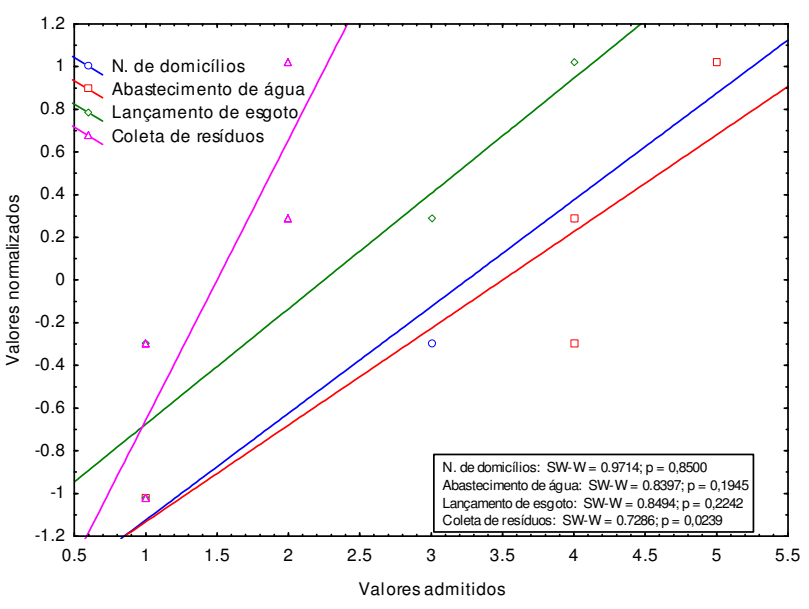

(c)

Figura 8: Teste Shapiro-Wilk aplicado a análise "Vulnerabilidade" x "Pressão": (a) Parque Estadual do Utinga na APA Belém; (b) Ilha do Combu; (c) Parque Antônio Danúbio.

Figure 8: Shapiro-Wilk test applied to "Vulnerability" x "Pressure" analysis: (a) Utinga State Park in EPA of Belém; (b) Combu Island; (c) Antônio Danúbio Park. 
A Figura 9 apresenta a análise das variáveis de "Estado" x "Risco" obtidas a partir da distribuição matricial para cada unidade (Figura 4 - Etapa 2): Parque Estadual do Utinga na Área de Proteção Ambiental de Belém (4 $x$ 28), Área de Proteção Ambiental llha do Combu (4 x 16) e Parque Ambiental de Ananindeua "Antônio Danúbio" (4 x 16).

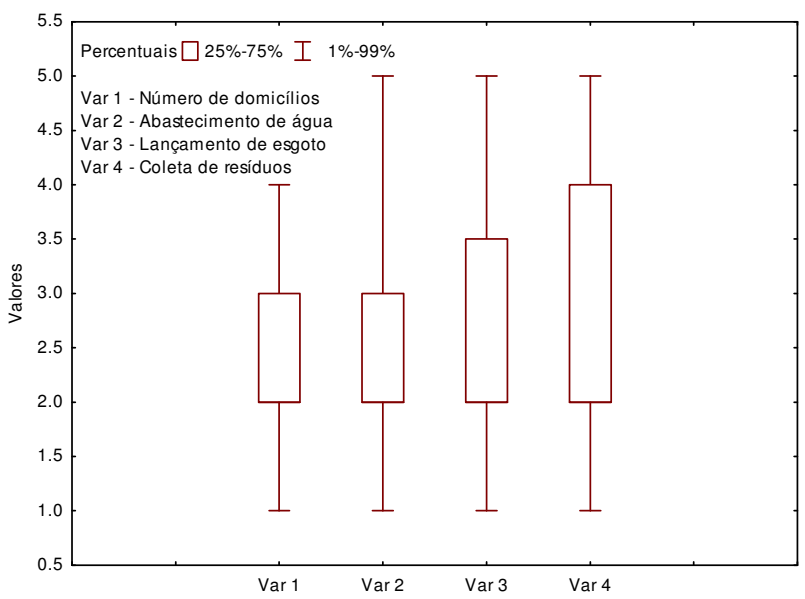

(a)

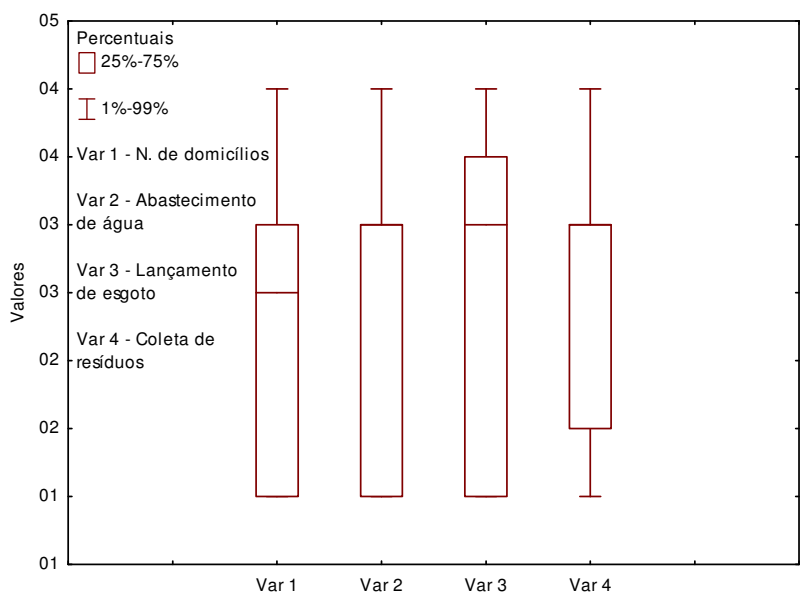

(b)

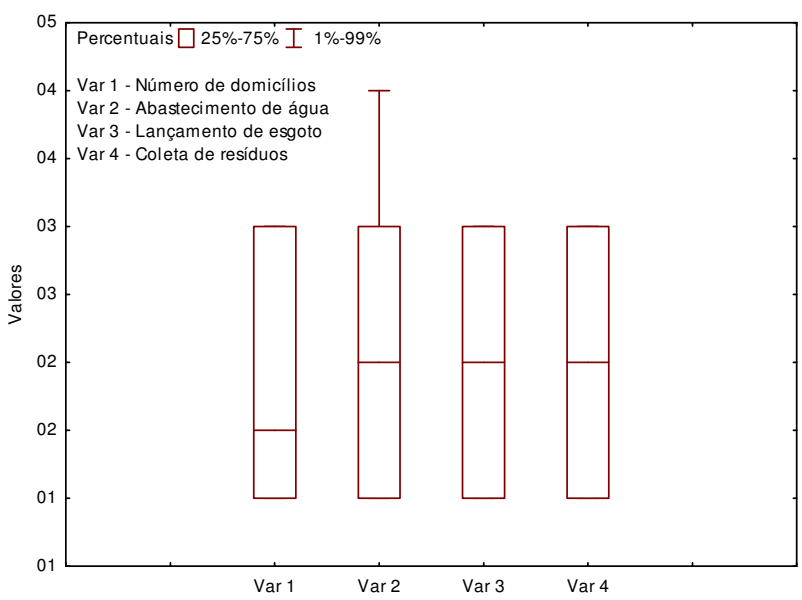

(c)

Figura 9: Análise de "Estado" x "Risco": (a) Parque Estadual do Utinga na APA Belém; (b) Illha do Combu; (c) Parque Antônio Danúbio.

Figure 9: Analysis of "state" x "Risk": (a) Utinga State Park in EPA of Belém; (b) Combu Island; (c) Antônio Danúbio Park. 
O risco admitido para as áreas de estudo apresenta maior variabilidade segundo os grandes grupos de estado avaliados no Utinga e maior regularidade nas unidades do Combu e Antônio Danúbio. No Parque Estadual do Utinga na APA Belém foi possível observar que os biogeoindicadores representados pela vulnerabilidade, são mais abrangentes, pois apresentam os fatores fauna terrestre, pesca e extrativismo.

Etto et al. (2013) citam que as mudanças em bordas de áreas protegidas podem ocasionar alterações no meio biótico, que são decorrentes das transformações impostas ao meio físico, provocando variações diretas, que correspondem à mudança de distribuição e densidade de indivíduos de uma mesma espécie e indiretas relacionadas as interações entre as diversas espécies encontradas, como a dispersão de sementes, polinização, predação e parasitismo.

Esses indicadores quando relacionados com a pressão de domicílios, demonstram níveis elevados. Existe um fácil acesso da comunidade com o interior do Parque Estadual do Utinga na APA Belém justificado pela ausência de áreas de amortecimento, da ineficácia da fiscalização, ao elevado tamanho da UC e a falta de sensibilização da população do entorno.

Marandola Jr. e Modesto (2012) afirmam que a percepção do ambiente é necessária para captar as consequências do envolvimento com o lugar e suas nuances; no geral a população nativa (não migrantes), presente antes da metropolização tem maior envolvimento com as condições "originais" dando maior valor ao ambiente ecológico, que os migrantes, que buscam ocupar novos espaços, independentemente da condição de restrição (ambiente ecológico) existente.

A Ilha do Combu ocupa a segunda média de risco, sendo a intermediaria entre Utinga e Antônio Danúbio. Na etapa da análise de risco foi possível observar que os indicadores de maior peso estavam relacionados com saneamento básico (rede de esgoto e água) e principalmente com o lixo.

Lobo et al. (2013) apresentam que na região conhecida como Baía do Guajará (a ilha do Combu localiza-se na foz do rio Guamá com a Baía do Guajará) existem sérios fatores que condicionam a vida da população ribeirinha que habita as ilhas da região, estes vão desde a água para consumo humano, lançamento de resíduos no solo e nas águas, lançamento in natura de esgotos provenientes do continente e a dificuldade de atendimento as questões de saúde e infraestrutura urbana básica (iluminação, segurança, transporte); ocasionando assim um efeito de exclusão.

Rodrigues e Barbieri (2008) complementam que existe a necessidade de fomentar tecnologias sociais apropriadas (como o desenvolvimento de práticas de ecoturismo em ambientes de unidades de conservação) para a comunidade, gerando mudanças de comportamentos, atitudes e práticas que proporcionem transformações; neste sentido a comunidade é protagonista e não mera receptora da tecnologia e a tecnologia social compreenderia uma forma de produto, processo, técnicas ou metodologias replicáveis desenvolvidas na interação com a comunidade. 
Um dos grandes problemas enfrentado com o lixo na ilha é decorrente da infiltração de líquido residual no solo e pelo destino do mesmo, que é queimado pela maioria da população da ilha, ameaçando a fauna e flora, além da vida dos moradores com focos de incêndio. Jacobi et al. (2009) destacam que quase totalidade das queimadas é causada pelo homem, por razões muito variadas, como limpeza, preparo de plantios, desmatamentos, etc. Em áreas de campo, as queimadas constituem uma das tradições mais comuns, principalmente para eliminação de material (orgânico e inorgânico), limpeza de terrenos e desmate. Em campos nativos, a vegetação que renasce aparenta mais força e melhor aparência, só que, ao longo dos anos, as queimadas provocam a degradação gradativa do solo e das plantas e a migração de animais.

A UC do Parque Antônio Danúbio, apesar de estar inserido na RMB, apresenta uma área pequena, de fácil fiscalização, o que influencia em um resultado de risco mais baixo. De acordo com a primeira etapa da análise de risco foi possível inferir que os pesos mais elevados estavam relacionados com o saneamento básico e com o lixo. Os fatores mais preocupantes estavam relacionados com a infiltração de liquido residual no solo, visto que a maioria da população do entorno utiliza água de poços ou nascentes, além do escoamento do esgoto para corpos hídricos. No entorno do Parque Antônio Danúbio, apesar da ausência da área de amortecimento, a pressão causada pelos domicílios não é maior devido à presença de uma organização urbana.

Com base no discutido por Zanella et al. (2013) é possível associar a condição em que se encontra o Parque Antônio Danúbio a uma situação de vulnerabilidade socioambiental; onde ocorre uma dependência entre a estabilidade social do entorno e sua coexistência com os espaços naturais. Ou seja, a migração de grupos que apresentam desvantagens sociais pode implicar diretamente no aumento do risco das áreas ambientalmente vulneráveis (FIGUEIRÊDO et al., 2007), fator este já diagnosticado no entorno da APA Belém que abriga o Parque Estadual do Utinga.

As tendências observadas permitem identificar pontos relevantes sobre as práticas de ecoturismo desenvolvidas nestas áreas e suas possibilidades de aplicação futuras. Para a população do entorno do Parque do Utinga, é essencial demonstrar a importância da biodiversidade inserida nas unidades, além de ressaltar que a pesca e caça dentro da UC são consideradas crimes ambientais, trazendo riscos para a fauna silvestre.

A sensibilização e o despertar da consciência crítica de grupos sociais no entorno das UCs, além do estímulo da participação da comunidade na proteção dos recursos naturais, é considerado como uma das ações mais apropriadas para a efetiva proteção dessas áreas. Onde a melhor forma de despertar a conscientização crítica da população é através da execução de práticas de educação ambiental, que tem como desafio promover a mudança de valores e atitudes, integrando suas ações aos aspectos ecológicos, políticos, culturais e éticos conforme constatado por Cerati e Lazarini (2009).

De posse dos bio-geoindicadores referente às UCs foram propostas medidas de manejo (Tabela 3). As práticas de ecoturismo identificadas como potenciais para as três unidades são: trilhas ecológicas interpretativas (com 
destaque para a fauna e flora locais), práticas de educação ambiental (voltadas a valorização dos recursos naturais) e atividades de lazer e esportivas (passeios de canoa, corridas).

Tabela 3: Relação entre bio-geoindicadores $\mathrm{x}$ medidas de manejo $\mathrm{x}$ práticas de ecoturismo propostas paras UCs de estudo.

Table 3: Relationship between bio-geoindicators $x$ management measures $x$ management practices of ecotourism proposals for units of study.

\begin{tabular}{|c|c|c|c|}
\hline Local & Bio-geoindicadores & Medidas de manejo & $\begin{array}{c}\text { Práticas de ecoturismo } \\
\text { propostas }\end{array}$ \\
\hline \multirow{5}{*}{$\begin{array}{l}\text { Parque } \\
\text { Ambiental do } \\
\text { Utinga }\end{array}$} & $\begin{array}{l}\text { Áreas verdes } \\
\text { (cobertura florestal da } \\
\text { área do Parque) }\end{array}$ & $\begin{array}{l}\text { Plantio de espécies } \\
\text { nativas em áreas } \\
\text { desmatadas }\end{array}$ & $\begin{array}{l}\text { Trilhas interpretativas, caminhadas } \\
\text { em trilhas com a valorização dos } \\
\text { aspectos ecológicos locais }\end{array}$ \\
\hline & $\begin{array}{l}\text { Fauna terrestre livre } \\
\text { do Parque }\end{array}$ & $\begin{array}{l}\text { Maior fiscalização nas } \\
\text { áreas do entorno, } \\
\text { principalmente no } \\
\text { controle de invasões }\end{array}$ & $\begin{array}{l}\text { Caminhada na trilha com um guia } \\
\text { especialista em animais silvestres, } \\
\text { elaboração de um catálogo } \\
\text { representativo }\end{array}$ \\
\hline & Ictiofauna dos lagos & $\begin{array}{l}\text { Fiscalização da pesca } \\
\text { ilegal }\end{array}$ & $\begin{array}{l}\text { Um pequeno museu com animais } \\
\text { empalhados representado a fauna } \\
\text { do Parque. }\end{array}$ \\
\hline & $\begin{array}{l}\text { Fluxo de água que } \\
\text { drena em direção ao } \\
\text { Parque (igarapés e } \\
\text { aquíferos livres) }\end{array}$ & $\begin{array}{l}\text { Recuperação do } \\
\text { padrão de qualidade da } \\
\text { água buscando atingir } \\
\text { a Classe I }\end{array}$ & $\begin{array}{l}\text { Incentivo ao desenvolvimento de } \\
\text { práticas que não interfiram na } \\
\text { qualidade das áreas, com destino } \\
\text { de alguns cursos d'água para } \\
\text { atividades de esporte e lazer como } \\
\text { passeios de canoa }\end{array}$ \\
\hline & $\begin{array}{l}\text { Cobertura de solo } \\
\text { (espessura) que } \\
\text { recebe diretamente o } \\
\text { escoamento } \\
\text { superficial (pluvial, } \\
\text { esgotamento } \\
\text { sanitário) }\end{array}$ & $\begin{array}{l}\text { Elaboração de ações } \\
\text { de saneamento básico } \\
\text { principalmente } \\
\text { associadas a retirada } \\
\text { de resíduos e a } \\
\text { remoção de sistemas } \\
\text { de drenagem (água e } \\
\text { esgoto) que drenam } \\
\text { em direção ao parque }\end{array}$ & $\begin{array}{l}\text { Restauração ambiental das áreas } \\
\text { degradadas, com adaptação das } \\
\text { mais próximas as bordas do } \\
\text { parque como espaços públicos } \\
\text { para recreação e valorização do } \\
\text { patrimônio ambiental }\end{array}$ \\
\hline \multirow{3}{*}{$\begin{array}{l}\text { Parque } \\
\text { Ambiental } \\
\text { Antônio } \\
\text { Danúbio }\end{array}$} & $\begin{array}{l}\text { Áreas verdes } \\
\text { (cobertura florestal da } \\
\text { área do Parque) }\end{array}$ & $\begin{array}{l}\text { Plantio de espécies } \\
\text { nativas }\end{array}$ & $\begin{array}{l}\text { Trilhas interpretativas, caminhadas } \\
\text { em trilhas }\end{array}$ \\
\hline & $\begin{array}{l}\text { Fluxo de água que } \\
\text { drena em direção ao } \\
\text { Parque (igarapés e } \\
\text { aquíferos livres) }\end{array}$ & $\begin{array}{l}\text { Recuperação do } \\
\text { padrão de qualidade da } \\
\text { água buscando atingir } \\
\text { a Classe I }\end{array}$ & $\begin{array}{l}\text { Criação de espaços } \\
\text { contemplativos e representativos } \\
\text { do ecossistema local }\end{array}$ \\
\hline & $\begin{array}{l}\text { Cobertura de solo } \\
\text { (espessura) que } \\
\text { recebe diretamente o } \\
\text { escoamento } \\
\text { superficial (pluvial, } \\
\text { esgotamento } \\
\text { sanitário) }\end{array}$ & $\begin{array}{l}\text { Elaboração de ações } \\
\text { de saneamento básico } \\
\text { principalmente } \\
\text { associadas a remoção } \\
\text { de sistemas de } \\
\text { drenagem (água e } \\
\text { esgoto) que drenam } \\
\text { em direção ao parque }\end{array}$ & $\begin{array}{l}\text { Recuperação de áreas verdes com } \\
\text { restauração faunística e florística }\end{array}$ \\
\hline \multirow{3}{*}{$\begin{array}{l}\text { Ilha do } \\
\text { Combu }\end{array}$} & $\begin{array}{l}\text { Áreas verdes } \\
\text { (cobertura florestal da } \\
\text { área do Parque) }\end{array}$ & $\begin{array}{l}\text { Preservar as áreas } \\
\text { verdes }\end{array}$ & $\begin{array}{l}\text { Realizar atividades de EA e Trilhas } \\
\text { interpretativas }\end{array}$ \\
\hline & $\begin{array}{l}\text { Fluxo de água que } \\
\text { drena em direção ao } \\
\text { Parque (igarapés e } \\
\text { aquíferos livres) }\end{array}$ & $\begin{array}{l}\text { Tratar a água e } \\
\text { construir uma rede de } \\
\text { abastecimento }\end{array}$ & $\begin{array}{l}\text { Criação de espaços } \\
\text { contemplativos e representativos } \\
\text { do ecossistema local }\end{array}$ \\
\hline & $\begin{array}{l}\text { Cobertura de solo } \\
\text { (espessura) que } \\
\text { recebe diretamente o } \\
\text { escoamento } \\
\text { superficial (pluvial, } \\
\text { esgotamento } \\
\text { sanitário) }\end{array}$ & $\begin{array}{l}\text { Elaboração de ações } \\
\text { de saneamento básico } \\
\text { principalmente } \\
\text { associadas a retirada } \\
\text { de resíduos e a a } \\
\text { criação de uma rede de } \\
\text { abastecimento local }\end{array}$ & $\begin{array}{l}\text { Atuar na organização do processo } \\
\text { de valorização do patrimônio } \\
\text { natural da ilha junto aos } \\
\text { moradores locais e comerciantes }\end{array}$ \\
\hline
\end{tabular}


O plantio de espécies nativas com a ajuda dos visitantes dentro das UCs de Ananindeua e Utinga auxiliaria para preservação e conservação das áreas verdes (cobertura florestal da área do parque), evitando inclusive o surgimento de outras espécies que não fossem da região.

Em todas as UCs há um grande déficit no saneamento, a realização de atividades envolvendo educação ambiental ajudaria na conscientização para o não agravamento da situação. Com relação cursos d'água que drenam em direção as UCs, a maior parte está ameaçada pela falta de saneamento, principalmente as UCs de Antônio Danúbio e Utinga.

A Tabela 1 resume as proposições adotadas, demonstrando que são necessárias ações integradas entre o poder público e as voltadas para 0 desenvolvimento do potencial dos parques. Isto decorre da maioria das vezes, do planejamento territorial geralmente encontrar-se desvinculado do espaço natural.

A discussão sobre as formas de aproveitamento dos espaços urbanos, considerando as demandas socioeconômicas dos municípios e a necessidade de manutenção dos espaços naturais, abordada por vários autores (DUTRA et al., 2008; LOUREIRO; CUNHA, 2008; GONÇALVES et al., 2011; SILVA et al., 2013; KUHLMANN et al., 2014) indica que há necessidade do envolvimento efetivo dos grupos sociais mais afetados pela existência das áreas protegidas. Onde para se assegurar um processo participativo é preciso desenvolver ações de mobilização e envolvimento, que garantam a minimização dos condicionantes de vulnerabilidade socioambiental. Para tanto, o planejamento vinculado a gestão ambiental deve considerar as desigualdades existentes.

O planejamento voltado ao desenvolvimento de práticas de ecoturismo visa promover o entendimento e a divulgação do conhecimento sobre a biodiversidade e as consequências de sua perda. Para isso, faz-se necessário sensibilizar e despertar a consciência crítica da população do entorno das UCs e estimular a participação da comunidade na proteção dos recursos naturais.

\section{Conclusão}

As relações entre as demandas de preservação/conservação das unidades de conservação e as práticas de ecoturismo foram confirmadas ao longo do desenvolvimento da pesquisa. O levantamento realizado identificou um processo de ocupação do entorno dos Parques como o principal agravante. O Parque Estadual do Utinga localizado na Área de Proteção Ambiental de Belém apresenta o maior impacto, visto que se localiza dentro da Região Metropolitana de Belém e seu entorno encontra-se próximo de áreas de alta vulnerabilidade social. A ilha do Combu não sofre a pressão do impacto imobiliário, porém tem relações comerciais com o continente, além de receber uma grande quantidade de lixo de Belém, carregado pelos rios.

A metodologia aplicada mostrou-se adequada para esta proposta de avaliação, porém o aumento significativo do número de variáveis demanda por ferramentas computacionais que possibilitem o cruzamento múltiplo mais eficiente. O observado é que as áreas enfocadas devem ter um 
gerenciamento que contemple sua vocação como unidades de conservação e o crescimento das cidades. A Ilha do Combu considerada o ambiente mais conservado está em constante ameaça, uma vez que a proximidade de Belém possibilita diversos níveis de interface desde o social ao econômico, e todos tendo reflexos na questão ambiental.

Ao final este trabalho visa alertar que estas regiões devem ser incorporadas a formas planejamento (ambiental, urbano) de curto e longo prazos que visem reduzir a situação de risco instalada, iniciando pela área de maior prioridade que é a APA Belém/Parque Estadual do Utinga, cujo grau de evolução já compromete a preservação dos recursos naturais inicialmente projetada.

\section{Referências bibliográficas}

BAHIA, V.; LUIZ, J.G.; LEAL, L.R.B.; MORALES, G.P.; NOBERT, F.N. Investigação da potencialidade de contaminação no Parque estadual do Utinga em Belém (PA) utilizando o método geofísico georadar. Águas Subterrâneas, v. 24, n. 1, p.: 85102, 2010.

BAÍA JÚNIOR, P.C.; GUIMARÃES, D.A.A. Parque Ambiental de Belém: um estudo da conservação da fauna silvestre local e a interação desta atividade com a comunidade do entorno. Revista Científica da UFPA, n. 4, p.: 1-18, 2--4.

BEZERRA, T.M.O.; GONÇALVES, A.A.C. Concepções de meio ambiente e educação ambiental por professores da Escola Agrotécnica Federal de Vitória de Santo Antão - Pernambuco. Biotemas, v. 20, n. 3, p.: 115-125, 2007.

BORJA, A.; GALPARSORO, I.; SOLAUN, O.; MUXIKA, I.; TELLO E.; URIARTE, A.; VALENCIA, V. The European Water Framework Directive and the DPSIR, a methodological approach to assess the risk of failing to achieve good ecological status. Estuarine, Coastal and Shelf Science, v. 66, p. 84-96, 2006.

BRASIL. Sistema Nacional de Unidades de Conservação. Brasília: Instituto Chico Mendes de Conservação da Biodiversidade - ICMBIO, 2012, 67p.

BRASIL. Ecoturismo: orientações básicas. Brasília: Ministério do Turismo, 2010, 91p.

CERATI, T. M.; LAZARINI, R.A.M. A Pesquisa-Ação em Educação Ambiental: uma experiência no entorno de uma unidade de conservação urbana. Ciência e Educação, v. 15, n. 2, p.: 383-392, 2009.

CONCEIÇÃO, R.S.; COSTA, N.M.C.; COSTA, V.C. A importância da evolução do uso do solo como geoindicador para o planejamento do Ecoturismo em Unidades de Conservação: aplicação no Parque Estadual da Pedra Branca (RJ). Revista Brasileira de Ecoturismo, v. 3, n. 3, p.: 408-427, 2010.

DUTRA, V.; COLARES, A.; ADORNO, L.F.M.; MAGALHÃES, K.; GOMES, K. Proposta de estradas-parque como unidade de conservação: dilemas e diálogos entre o Jalapão e a Chapada dos Veadeiros. Sociedade e Natureza, v. 20, n. 1, p.: 161-176, 2008.

ETTO, T.L.; LONGO, R.M.; ARRUDA, D.R.; INVENIONI, R. Ecologia da paisagem de remanescentes florestais na bacia hidrográfica do Ribeirão das Pedras Campinas -SP. Revista Árvore, v. 37, n. 6, p.: 1063-1071, 2013. 
FERREIRA, L.V.; VENTINQUE, E.; ALMEIDA, S. O desmatamento na Amazônia e a importância das áreas protegidas. Estudos Avançados, v. 19, n. 53, p.: 1-10, 2005.

FIGUEIRÊDO, M.C.B.; TEIXEIRA, A.S.; ARAÚJO, L.F.P.; ROSA, M.F.; PAULINO, W.D.; MOTA, S.; ARAÚJO, J.C. Avaliação da vulnerabilidade ambiental de reservatórios à eutrofização. Engenharia Sanitária e Ambiental, v. 12, n. 4, p.: 399-409, 2007.

FREITAS, C. E. C.; SIQUEIRA-SOUZA, F. K. O uso de peixes como bioindicador embiental em áreas de várzea da bacia amazônica. Revista Agrogeoambiental, v. 1, n. 2, p.: 39-45, 2009.

GONÇALVES, M.P.; BRANQUINHO, F.T.B.; FELZENSZWALB, I. Uma análise contextual do funcionamento efetivo e participação popular em uma unidade de conservação: o caso da área de proteção ambiental de Petrópolis (Rio de Janeiro: Brasil). Sociedade e Natureza, v. 23, n. 2, p.: 323-334, 2011.

GOULART, M. D. C.; CALLISTO, M. Bioindicadores de qualidade de água como ferramenta em estudos de impacto ambiental. Revista da FAPAM, ano 2, n.1, p.: 19, 2003.

JACOBI, L.F.; LÚCIO, A.D.; STORCK, L.; LOPES, S.J.; CARGNELUTTI FILHO, A. Caracterização das queimadas acidentais em campo, no Município de Santa Maria -RS. Ciência Rural, v. 39, n. 3, p.: 904-908, 2009.

JÚNIOR, P. F.; VILLA, M. E. C. D. O ambiente geográfico e os geoindicadores. Revista Brasileira de Geografia Física, v. 4, n. 2, p.: 337-348, 2011.

KUHLMANN, M.L.; IMBIMBO, H.R.V.; OGURA, L.L.; VILLANI, J.P.; STARZYNSKI, R.; ROBIM, M.J. Effects of human activities on rivers located in protected areas of the Atlantic Forest. Acta Limnologica Brasiliensia, v. 26, n. 1, p.: 60-72, 2014.

LAMOSO, L.P.; LOMBA, R.M. Transformações socioespaciais no munícipio de Bonito - Mato Grosso do Sul após introdução do ecoturismo. RA'EGA, v. 11, n. 14, p.: 129-138, 2006.

LOBO, M.A.A.; LIMA, D.M.B.; SOUZA, C.M.N.; NASCIMENTO, W.A.; ARAÚJO, L.C.C.; SANTOS, N.B. Avaliação econômica de tecnologias sociais aplicadas à promoção de saúde: abastecimento de água por sistema SODIS em comunidades ribeirinhas da Amazônia. Ciência e Saúde Coletiva, v. 18, n. 7, p.: 2119-2127, 2013.

LOUREIRO, C.F. B.; CUNHA, C.C. Educação ambiental e gestão participativa de unidades de conservação: elementos para se pensar a sustentabilidade democrática. Ambiente e Sociedade, v. 11, n. 2, p.: 237-253, 2008.

MARANDOLA JR., E.; MODESTO, F. Percepção dos perigos ambientais urbanos e os efeitos de lugar na relação população-ambiente. Revista Brasileira de Estudos de População, v. 29, n. 1, p.: 7-35, 2012.

MESTRE, L.A.M.; GASNIER, T.R. Populações de aranhas errantes do gênero Ctenus em fragmentos florestais na Amazônia Central. Acta Amazônica, v. 38, n. 1, p.: 159-164, 2008.

OECD. Water Governance in OECD Countries: a multi-level approach. Paris: OECD Environment Directorate, 245p. 
PEDRINI, A.G. Avaliação da educação ambiental no ecoturismo (em trilhas) no Brasil: Uma proposta baseada na qualidade conceitual. OLAM Ciência e Tecnologia, v. 6, n. 2, p.: 83-106, 2006.

RAZALI, N.M.; WAH, Y.B. Power comparisons of Shapiro-Wilk, KolmogorovSmirnov, Lilliefors and Anderson-Darling tests. Journal of Statistical Modeling and Analytics, v. 2, n. 1, p.: 21-33, 2011.

RODRIGUES, I.; BARBIERI, J.C. A emergência da tecnologia social: revisitando o movimento da tecnologia apropriada como estratégia de desenvolvimento sustentável. Revista de Administração Pública, v. 42, n. 6, p.: 1069-1094, 2008.

RISSIK, D.; COX, M.; MOSS, A.; ROSE, D.; SCHELTINGA, D.; NEWHAM, L.T.H.; ANDREWS, A.; BAKER-FINCH, S.C. VPSIRR (Vulnerability - Pressure - State Impact - Risk And Response): an approach to determine the condition of estuaries and to assess where management responses are. In: ZERGER, A.; ARGENT, R M. MODSIM - Modelling and Simulation. Melbourne/Australia, p.: 170-176, 2005.

SILVA, A.C.C.; PRATA, A.P.N.; SOUTO, L. S.; MELLO, A. A. Aspectos de ecologia de paisagem e ameaças à biodiversidade em uma unidade de conservação na Caatinga, em Sergipe. Revista Árvore, v. 37, n. 3, p.: 479-490, 2013.

SILVA, C.E.; PINTO, J.B.; GOMES, L.J. Ecoturismo na Floresta Nacional do Ibura como potencial fomento de sociedades sustentáveis. Revista Nordestina de Ecoturismo, Aracaju, v. 1, n. 1, p.: 6-17, 2008.

SILVA, D.S.; MARQUES, E.E.; LOLIS, S.F. Macrófitas aquáticas: "vilãs ou mocinhas"? Interface, n. 4, p.: 17-27, 2012.

SONG, X.; FROSTELL, B. The DPSIR framework and a pressure-oriented water quality monitoring approach to ecological river restoration. Water, v. 4, p. 700-712, 2012.

TAVARES, A.B.; CRUZ, S.P.; LOLLO, J.A. Geoindicadores para a caracterização de estados de diferentes ambientes. Estudos Geográficos, v. 5, n. 2, p.: 42-57, 2007.

VARELA, M.C.; CARVALHO, R.G. Viabilidade ambiental para a criação de unidades de conservação na ilha da coroa, Mossoró/RN. Sociedade e Natureza, v. 21, n. 2, p.: 7-21, 2009.

VASCONCELOS, M.; MAGALHÃES, V.; SOUZA, F.C. Caracterização dos parâmetros de qualidade da água do manancial Utinga, Belém, PA, Brasil. Revista Ambiente e Água, v. 6, n. 2, p.: 305-324, 2011.

ZANELLA, M.E.; OLIMPIO, J.L.; COSTA, M.C.L.; DANTAS, E.W. C. Vulnerabilidade socioambiental do baixo curso da bacia hidrográfica do Rio Cocó, Fortaleza-CE. Sociedade e Natureza, v. 25, n. 2, p.: 317-332, 2013. 
Joyce Ferreira Macedo de Andrade Fidélis: Centro Universitário do Estado do Pará, Belém, PA, Brasil.

E-mail: joyce.fma@hotmail.com.

Link para o currículo Lattes: http://lattes.cnpq.br/7074020271779379

Sérgio Queirós Lima: Universidade Federal do Pará, Belém, PA, Brasil.

E-mail: sergio.lima_90@hotmail.com.

Link para o currículo Lattes: http://lattes.cnpq.br/1851446863675819

Aline Maria Meiguins de Lima: Universidade Federal do Pará, Belém, PA, Brasil.

E-mail: alinemeiguins@gmail.com.

Link para o currículo Lattes: http://lattes.cnpq.br/6572852379381594

Márcia Nágem Krag: Universidade Federal Rural da Amazônia, Belém, PA, Brasil.

E-mail: marcia.nagem.krag@gmail.com.

Link para o currículo Lattes: http://lattes.cnpq.br/3985771068576167

Quêzia Leandro de Moura Guerreiro: Universidade Federal do Pará, Belém, PA, Brasil.

E-mail: queziamoura@hotmail.com.

Link para o currículo Lattes: http://lattes.cnpq.br/2392493799166491

Data de submissão: 12 de agosto de 2014

Data de recebimento de correções: 07 de abril de 2015

Data do aceite: 07 de abril de 2015

Avaliado anonimamente 